\title{
Natural UVB exposure changes the species composition of Antarctic phytoplankton in mixed culture
}

\author{
A. T. Davidson ${ }^{1,2, *}$, H. J. Marchant ${ }^{1}$, W. K. de la Mare ${ }^{1}$ \\ ${ }^{1}$ Australian Antarctic Division, Channel Highway, Kingston, Tasmania, 7050 Australia \\ ${ }^{2}$ Institute of Antarctic and Southern Ocean Studies, University of Tasmania, PO Box 252c, Hobart, Tasmania, 7001 Australia
}

\begin{abstract}
Numerous investigators have demonstrated marked interspecific differences in tolerance of Antarctic marine phytoplankton to UVB exposure. Consequent changes in species composition have been proposed but as yet not demonstrated. We conducted competition experiments in which mixed cultures of Antarctic marine diatoms and colonial and flagellate stages in the life cycle of the haptophyte Phaeocystis antarctica were exposed to natural Antarctic solar irradiance. Results demonstrated UVB-induced changes in species composition favouring the colonial stage of $P$. antarctica following $2 \mathrm{~d}$ exposure or less. These data indicate the potential for altered trophodynamics and carbon flux in Antarctic waters as a result of ozone depletion. Our results also show the limited predictive value of results obtained using UVB exposures above those likely to be experienced in the natural environment.
\end{abstract}

KEY WORDS: UVB radiation $\cdot$ Antarctic phytoplankton $\cdot$ Species composition

\section{INTRODUCTION}

Stratospheric ozone concentrations over Antarctica presently fall to less than $30 \%$ of pre-ozone-hole values during spring (Weiler \& Penhale 1994). Springtime UVB irradiance is at least as high as that at the summer solstice (Lubin et al. 1989). Melting sea-ice forms a shallow pycnocline in the marginal ice zone (MIZ) which may confine phytoplankton to depths of $20 \mathrm{~m}$ or less for up to $6 \mathrm{~d}$ (Mitchell \& Holm-Hansen 1991, Veth 1991). Phytoplankton blooms in the high light, high nutrient environment of the MIZ contribute 25 to $67 \%$ of phytoplanktonic production in the Southern Ocean (Smith \& Nelson 1986).

Survival, growth and photosynthesis of phytoplankton in the MIZ are reduced by UVB exposure (Smith et al. 1992) as they coincide with the springtime ozone depletion (Helbling et al. 1994). It has been suggested that exposure of phytoplankton to increased UVB radiation is likely to alter species composition (Calkins \& Thordardottir 1980, Karentz 1991, Smith et al. 1992, Davidson et al. 1994). Such changes have been

\footnotetext{
•E-mail: andrew_dav@antdiv.gov.au
}

reported from experimental microcosms in temperate environments using artificially increased UVB irradiance (Worrest et al. 1978, 1981). Interspecific differences in the tolerance of Antarctic phytoplankton to UVB have been reported (Karentz et al. 1991a, Marchant et al. 1991). However, direct evidence of changes in species composition has not been reported for the Southern Ocean.

Species specific investigations of the tolerance of phytoplankton to UVB irradiance are important in predicting the effect of ozone depletion (Karentz 1991, Davidson et al. 1994). However, such studies do not include the competitive interactions between phytoplankton species during UVB exposure. Here we report that exposure of mixed cultures of Antarctic phytoplankton to natural and attenuated Antarctic UV irradiance produced changes in phytoplankton species composition.

\section{MATERIALS AND METHODS}

Unialgal strains of the diatoms Chaetoceros simplex Ostenfeld, Fragilariopsis lecointei V. H., Fragilariopsis 
curta (V. H.) Hasle, Thalassiosira tumida (Jan.) Hasle, Proboscia (Rhizosolenia) alata (Brightwell) Sundström and the haptophyte Phaeocystis antarctica Karsten were isolated from Prydz Bay, Antarctica. Cultures were maintained under cool white fluorescent light at a photosynthetically active radiation (PAR) intensity of $5.11 \mathrm{~W} \mathrm{~m}^{-2}$ and at $0^{\circ} \mathrm{C}$ with an 18:6 h light:dark cycle. Exponentially growing cultures of the 6 species (that of $P$. antarctica containing approximately equal concentrations of the flagellate and colonial life stages) were diluted 1:5, culture:fresh culture medium, 5 and $2 \mathrm{~d}$ before starting the experiment. Organisms in $10 \mathrm{ml}$ subsamples of each monospecific culture were fixed with buffered Lugol's solution and the cell concentration estimated using the Utermöhl sedimentation technique over 15 replicate randomly chosen fields using an inverted microscope. Aliquots of each culture were mixed to give approximately equal cell concentrations of each species and both $P$. antarctica life stages. Three $10 \mathrm{ml}$ subsamples were removed to determine cell concentrations (as above) of each species at time 0 . Nine subsamples, each of $500 \mathrm{ml}$, were then transferred to polythene bags (WhirlPak, Nasco) which transmit light above $220 \mathrm{~nm}$. Three replicate bags were each exposed to one of 3 light treatments; unscreened (PAR, UVA and UVB treatment), Mylar screened (which transmitted wavelengths above $320 \mathrm{~nm}$ : PAR + UVA treatment), and polycarbonate screened (which transmitted wavelengths above $370 \mathrm{~nm}$ : PAR treatment) (Davidson \& Marchant 1994).

Mixed phytoplankton populations were incubated for $8 \mathrm{~d}$ at Davis Station, Antarctica $\left(68^{\circ} 35^{\prime} \mathrm{S}, 78^{\circ} \mathrm{E}\right)$ at a depth of $0.2 \mathrm{~m}$ between 10 and 18 December 1992 in an outdoor tank through which sea water was circulated. Thus, the phytoplankton were exposed to near-surface natural light irradiance. Integrated irradiances were measured using an IL 1700 research radiometer equipped with UVA and erythemal UVB sensors (Davidson \& Marchant 1994) which were calibrated to solar irradiances using the sensor response curve and a Macam spectroradiometer and erythemal UVB biometer respectively. Sensors were positioned beside phytoplankton at $0.2 \mathrm{~m}$ depth and the UVA and UVB irradiance integrated during incubation.

A subsample of $10 \mathrm{ml}$ was removed from each replicate treatment at $2 \mathrm{~d}$ intervals for $8 \mathrm{~d}$ and the concentration of each species determined (as above). The cell concentrations of each species after each period of irradiation were used to estimate a single exponential growth rate for each replicate. This provided independent estimates of growth rate, with estimated variances for each species under each of the 3 UV treatments. Exponential $\left(\log _{e}\right)$ growth rate estimates were obtained as the slope parameters of a generalised linear model (GLM) (see Chambers \& Hastie 1993), using the S-Plus statistical package with Gaussian errors, a log-link function, and weighted by the inverse of the square of the empirical standard error for each cell concentration determination.

The growth rate of cells of each species in the culture became the dependent variable in a fully crossed 2 way analysis of deviance (similar to an ANOVA, but allowing the inverse variances of the estimated growth rates to be used as weights) using a GLM with a Gaussian error model. Thus, growth rates of low variance received higher weight in statistical analysis than those with high variance. Growth rates across all species and by each species were compared between light treatments and presented as a box and whisker plot and interaction profile (see Fig. 1A, B). The flagellate and colonial life stages of Phaeocystis antarctica were considered to be functionally separate taxa due to the widely accepted physiological differences between these stages (e.g. Marchant et al. 1991, Davidson \& Marchant 1992b).

The size of 100 live cells of each species was measured and the mean cell volume calculated. Variation in the dimensions of cells fixed with Lugol's iodine from each light treatment were within 1 standard deviation of the live cell dimensions. The cell concentrations in replicates of each light treatment at each incubation time were pooled and the mean and standard error computed. Using the equations of Eppley et al. (1970) and the cell volume, carbon contributed by each species was then calculated. The carbon contributed by colonial stage Phaeocystis antarctica was likely to be an underestimate as colony matrix was not considered in the calculation.

To investigate the minimum duration of UV exposure required to cause changes in phytoplankton species composition, a $10 \mathrm{ml}$ subsample was removed from each replicate of all light treatments after $2,4,6$ and $8 \mathrm{~d}$ incubation and inoculated into $40 \mathrm{ml}$ of sterile $\mathrm{f} / 2$ medium in $50 \mathrm{ml}$ polystyrene culture flasks. Flasks were returned to culture maintenance conditions and grown for a further $9 \mathrm{~d}$ then thoroughly mixed and a $10 \mathrm{ml}$ subsample removed and counted (as above). This procedure of subculturing samples after the various durations of exposure allowed expression and amplification of changes in phytoplankton species composition, while avoiding the effects of nutrient limitation in culture. For each incubation time and light treatment, the mean proportion of the phytoplankton population contributed by each species following the $9 \mathrm{~d}$ amplification was calculated over 3 replicates. For these proportional data, error bars indicate \pm 1 standard error, calculated by arcsine square root transformation (after Zar 1984). 
Table 1. Cumulative integrated UVA and UVB irradiance during $8 \mathrm{~d}$ natural irradiation measured using an International Light research radiometer and light sensors

\begin{tabular}{|lcc|}
\hline $\begin{array}{l}\text { Irradiation } \\
(\mathrm{d})\end{array}$ & $\begin{array}{c}\text { Cum. integr. } \\
\text { UVA }\left(\mathrm{J} \mathrm{m}^{-2}\right)\end{array}$ & $\begin{array}{c}\text { Cum. integr. } \\
\text { erythemal UVB }\left(\mathrm{J} \mathrm{m}^{-2}\right)\end{array}$ \\
\hline 0 & 0 & 0 \\
2 & $9.75 \times 10^{5}$ & $6.48 \times 10^{3}$ \\
4 & $18.43 \times 10^{5}$ & $12.26 \times 10^{3}$ \\
6 & $28.51 \times 10^{5}$ & $19.74 \times 10^{3}$ \\
8 & $36.59 \times 10^{5}$ & $25.18 \times 10^{3}$ \\
\hline
\end{tabular}

\section{RESULTS AND DISCUSSION}

Weather conditions were intermittently sunny during the $8 \mathrm{~d}$ of exposure to natural Antarctic solar radiation. However, integrated UVA and UVB irradiances varied little during between-sample intervals (Table 1 ). Mean integrated UVA and UVB irradiance for each $2 \mathrm{~d}$ incubation period was $9.15 \pm 0.93 \times 10^{5}$ and $6.30 \pm 0.90$ $\times 10^{3} \mathrm{~J} \mathrm{~m}^{-2}$ respectively.

The analysis of deviance shows significant differences with species, light treatment and their interaction (Table 2). That species specific growth rates are significantly different is not surprising. The distributions of growth rates across species for the different UV treatments are shown in Fig. 1A. Although the main effect due to UV treatment is significant (Table 2), the effects are not substantial, and the statistical significance arises largely because of a few cases where growth rate estimates with low variances have received a high weight in the analysis. The unweighted means and medians of the growth rates across species are not significantly different between light treatments. Similarly, no significant difference was found in total calculated cell carbon concentration between light treatments (Fig. 2A). Thus, the overall growth and production by the community was maintained irrespective of light treatment.

In contrast, the interaction term is highly significant (Table 2). The changes in growth rates for at least some species under the different UV treatments demon-
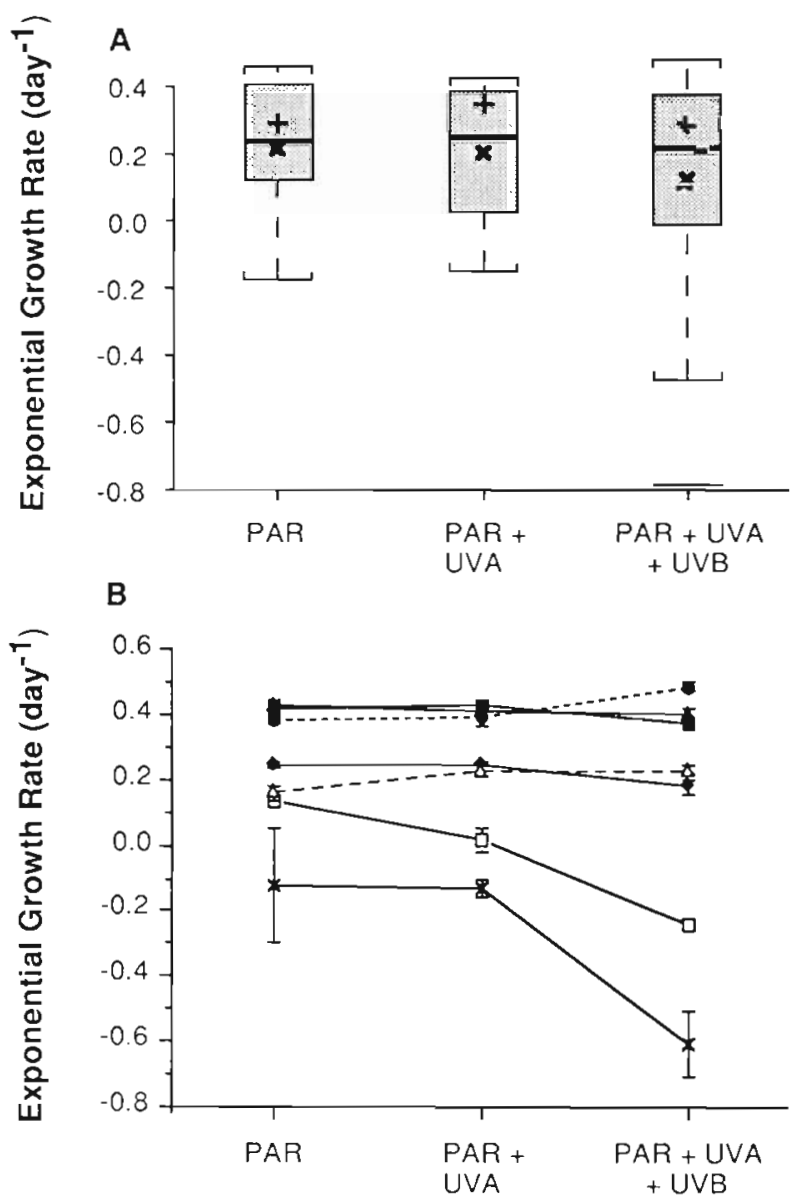

Light Treatment

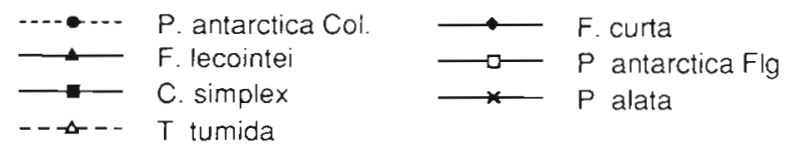

Fig. 1. Analysis of exponential growth rate $\left(d^{-1}\right)$ during $8 d$ exposure to natural irradiation. (A) Box and whisker plot showing similar growth rate across all species and comparing between light treatments and $(\mathrm{B})$ interaction profile showing UVB-dependent changes in the growth rate of each species between light treatments with the standard error over 3 replicates. Box and whisker plot shows mean weighted (+), unweighted $(\mathrm{x})$ and median (-) growth rates for all species between light treatments. Boxes enclose the interquartile range, whiskers extending to the standardised range and '- ' represents an outlier
Table 2. Two-way analysis of deviance showing the significance of UV effects on the growth of Antarctic phytoplankton species

\begin{tabular}{|lrrrrr|}
\hline Factor & df & Deviance & $\begin{array}{r}\text { Residual } \\
\text { df }\end{array}$ & $\begin{array}{r}\text { Residual } \\
\text { deviance }\end{array}$ & $\begin{array}{c}\text { Probability } \\
\chi^{2}\end{array}$ \\
\hline Null & & & & 62 & 2809.445 \\
Species & 6 & 2620.609 & 56 & 188.836 & 0.00000000 \\
UV treatment & 2 & 11.630 & 54 & 177.206 & 0.00298 \\
Species:UV interaction & 12 & 134.048 & 42 & 43.158 & 0.00000000 \\
& & & & & \\
\hline
\end{tabular}

strates that, over time, the species composition, in terms of cell concentration, will differ under the different UV regimes. Differences between the PAR and PAR + UVA light treatments, though significant $\left[p\left(\chi^{2}<0.01\right)\right]$, were only slight. Exposure to UVB caused substantial changes in the growth rates (Fig. 1B) which were statistically highly significant $\left[\mathrm{p}\left(\chi^{2}<0.000005\right)\right]$. 

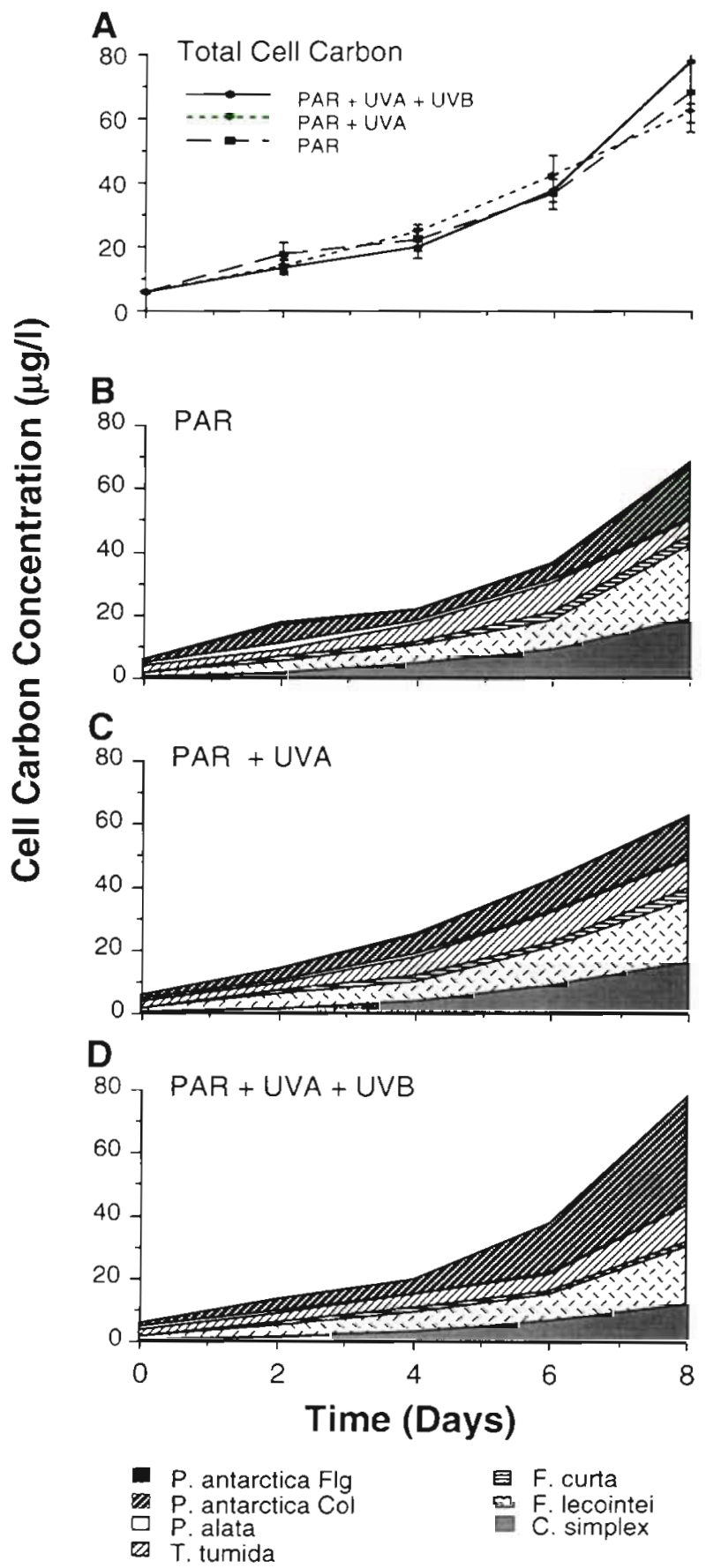

Fig. 2. Calculated cell carbon concentration of Antarctic phytoplankton during $8 \mathrm{~d}$ of natural irradiation showing $(\mathrm{A})$ total cell carbon across all species, and contributions by each species exposed to (B) PAR, (C) PAR + UVA and (D) PAR + UVA + UVB. P. antarctica Col and Flg indicate the colonial and flagellate life stage respectively. Error bars indicate standard error of the mean over 3 replicates

The growth rate of diatoms and the flagellate stage of Phaeocystis antarctica exposed to UVB either did not change significantly or declined. Only the colonial stage of $P$. antarctica showed a substantial promotion of growth as a result of exposure to UVB. The proportion of cell carbon contributed by diatoms and the flagellate stage of $P$. antarctica exposed to UVB also fell (Fig. 2B-D) but were replaced by colonial stage $P$. antarctica. Thus, Antarctic near-surface UVB irradiance alters phytoplankton species composition in culture.

The enhanced growth of colonial Phaeocystis antarctica when exposed to UVB agrees with earlier findings which demonstrated that exposure of unialgal cultures of this species to in situ UVB increased cell size, growth rate and production by the colonial stage (Davidson \& Marchant 1994) and may contribute to this species being one of the first to bloom in the ice and surface waters, where it frequently dominates the phytoplankton (Garrison et al. 1987, Fryxell \& Kendrick 1988, Davidson \& Marchant 1992a). Only Proboscia alata exhibited no significant growth in the absence of UV radiation (Fig. 1B). This may reflect the observed sensitivity of the species to mechanical disturbance during subculturing which leads to an extended lag phase in its growth.

Our results differ from those reported by other authors. McMinn et al. (1994) found that sediment cores from fjords in East Antarctica did not exhibit evidence of a significant change in species composition of the diatom community since springtime ozone depletion began. However, it is likely that persistent sea ice, which attenuates UVB by at least $90 \%$ (Trodahl \& Buckley 1989), provided shielding for these organisms. Bothwell et al. (1995) also criticise other aspects of the conclusions drawn by McMinn et al. (1994). Others (Smith et al. 1992, Karentz 1994, Karentz \& Spero 1995) have reported that exposure of diatoms and Phaeocystis antarctica to natural UVB did not alter their growth rates or that growth by $P$. antarctica declined.

Our study used natural solar irradiance and selected Antarctic phytoplankton species but did not simulate natural Antarctic conditions. We used a limited species assemblage grown in nutrient enriched media with and without exposure to a near-surface UVB light climate and wavelength structure. The effects of in situ UVB radiation on naturally occurring phytoplankton communities could differ from those we observed and the effect of increased UVB flux as a result of ozone depletion on phytoplankton species composition remains to be ascertained. Results obtained by Karentz (1994) for Phaeocystis antarctica were highly variable due to the clumped distribution of cells in colonies, changes within or between light treatments were seldom significant and, unlike Smith et al. (1992) and Davidson \& Marchant (1994), P. antarctica growth was also negative irrespective of light treatment. Differences between the results presented here and those of Smith et al. (1992) may be due to differences in 
methodology, the physiological state of cells or our use of cultured material and a multi-species mix. Karentz \& Spero (1995) report a strong positive correlation between $P$. antarctica concentration and column ozone concentration in the MIZ of the Bellingshausen Sea. The apparent conflict between their results and those presented here can only be reconciled with further study. Differences in methodology mean the studies are not directly comparable and it remains unclear whether the changes in $P$. antarctica concentration observed by Karentz \& Spero (1995) were directly related to changes in the in situ UVB climate during their study.

Our results also contrasted with our previous findings. The colonial stage in the life cycle of Phaeocystis antarctica produces high concentrations of UV-absorbing compounds (Marchant et al. 1991). These enhanced survival of its colonial stage when exposed to high UVB irradiances (Marchant et al. 1991) but diatoms, which largely lack UV absorbing compounds, survived UVB irradiances 3 to 5 times that which caused mortality in colonial $P$. antarctica (Davidson et al. 1994). Thus, the role of UV-absorbing compounds in alleviating UVB damage is questionable. Many Antarctic marine organisms possess UV-absorbing compounds (Karentz et al. 1991b). However, the presumed protection afforded organisms by such compounds remains largely unquantified. Results presented here show that growth by the colonial stage of $P$. antarctica was promoted under natural UVB exposure. Consequently, the UVB irradiance at which $P$. antarctica died (Marchant et al. 1991) was not indicative of its enhanced growth at sub-lethal natural irradiances. Nor was survival of diatoms up to far higher UVB irradiances than $P$. antarctica (Davidson et al. 1994) indicative of their slowed growth and production at these sub-lethal irradiances as here we show that $P$. antarctica dominates at their expense. The poor predictive value of a species response to high UVB irradiance experiments clearly demonstrates the limited value of extrapolating results of such experiments (Worrest et al. 1978, Karentz et al. 1991a, Marchant et al. 1991. Davidson et al. 1994) to the natural environment.

Vernet et al. (1994) found that high haptophyte concentrations in Antarctic waters correlated with high in situ absorption at $330 \mathrm{~nm}$ and low inhibition of photosynthesis when exposed to UVB. At sublethal natural UVB irradiances, metabolic processes such as photosynthesis apparently are shielded from damage by UV-absorbing compounds. Other metabolic costs of exposure to UVB are thereby minimised. Thus, at natural UVB irradiances colonial Phaeocystis antarctica may be afforded substantial protection by UV-absorbing compounds. High in situ absorption (Vernet et al. 1994) also suggests that blooms of $P$. antarctica may confer some UV protection on other organisms in the water column (Marchant et al. 1991), a feature not included in this experiment as colonial $P$. antarctica did not reach sufficient concentrations to attenuate UVB throughout the irradiated cultures.

The duration of UVB exposure required to elicit changes in phytoplankton species composition is critical in determining the potential magnitude of changes in phytoplankton species composition in Antarctic waters. Incubations of only 2 to $6 \mathrm{~d}$ may not have allowed expression of these changes in species composition. To express and amplify such changes, samples were removed from natural irradiation, subcultured, returned to culture maintenance conditions (which lack UV) and grown for a further $9 \mathrm{~d}$. Differences in proportional abundance of each species were not greatly increased by exposure times exceeding $2 \mathrm{~d}$ (Fig. 3). Thus, $2 \mathrm{~d}$ exposure to ambient near-surface UVB irradiance was sufficient to largely determine the UVB-mediated species composition. Exposure to UVA and UVA + UVB increased the proportion of colonial Phaeocystis antarctica in culture, mainly at the expense of Chaetoceros simplex (Fig. 3A, B). The proportion of total cells contributed by other species differed little between light treatments (Fig. 3C-E). Two days was the shortest natural exposure time investigated; the minimum exposure required to elicit changes in species composition remains unknown.

Results demonstrate that natural Antarctic UVB irradiance can alter phytoplankton species composition and also indicate that ozone depletion and the associated increase in UVB may promote the abundance of Phaeocystis antarctica relative to diatoms in Antarctic waters. This species accounts for some $10 \%$ of the total biogenic flux of dimethylsulfide (DMS) released to the atmosphere (Gibson et al. 1990). DMS is a principal source of sulfate cloud condensation nuclei and influences oceanic cloud cover (Charlson et al. 1987). P. antarctica also plays a pivotal role in determining the structure and function of the planktonic community (Garrison et al. 1987, Fryxell \& Kendrick 1988, Davidson \& Marchant 1992a). Its blooms produce high concentrations of dissolved organic carbon and slow-sinking mucilaginous particulate organic carbon which promote bacteria and microheterotrophs, but the large mucilaginous colonies of this alga are selectively avoided by many grazers (Davidson \& Marchant 1992b). Thus, any UVB-mediated increase in the abundance of $P$. antarctica could effect climate through changes in global albedo (Charlson et al. 1987) and significantly alter rates of vertical carbon flux and the particle size, form and availability of carbon to higher trophic levels (Marchant \& Davidson 1991). 


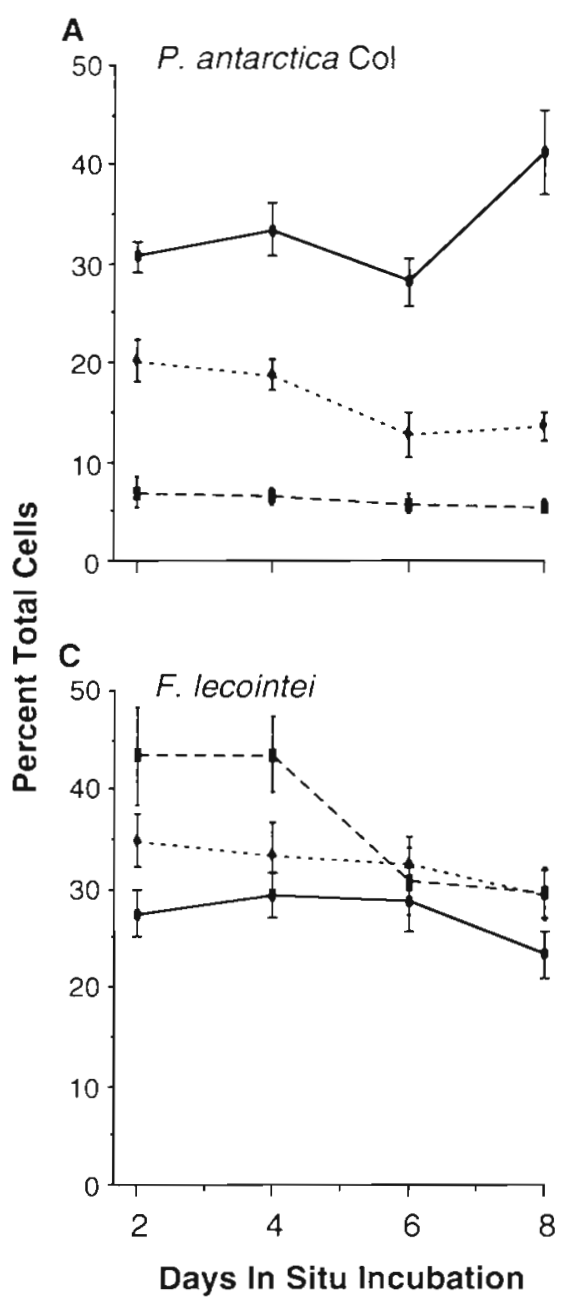

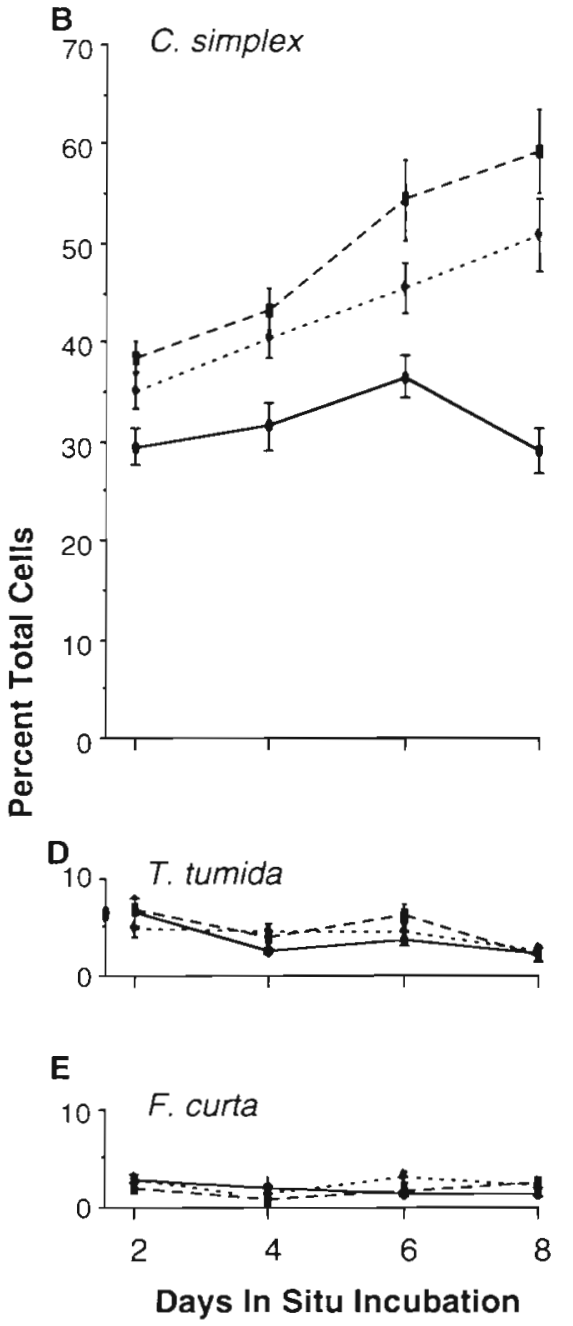

$$
\begin{array}{ll}
\longrightarrow- & \text { PAR + UVA + UVB } \\
\cdots \cdots & \text { PAR + UVA } \\
\cdots- & \text { PAR }
\end{array}
$$

Fig. 3. Changes in the percent of total cell concentration contributed by each species following natural exposure for $2,4,6$ and $8 \mathrm{~d}$, subculturing and a further $9 \mathrm{~d}$ growth. (A) colonial stage Phaeocystis antarctica (P. antarctica Col), (B) Chaetoceros simplex, (C) Fragilariopsis lecointei, (D) Thalassiosira tumida, (E) F. curta. Proboscia alata and the flagellate stage $P$. antarctica together contributed $<2 \%$ of the total cell concentration and their proportion did not alter significantly over the incubation times. Results represent mean proportions of 3 replicates and error bars indicate standard error calculated by arcsine square root transtormation after Zar (1984)

\section{LITERATURE CITED}

Bothwell ML, Karentz D, Carpenter EJ (1995) No UVB effect? Nature 374:601

Calkins J, Thordardottir T (1980) The ecological significance of solar UV radiation on aquatic organisms. Nature 283: 563-566

Chambers JM, Hastie TJ (1993) Statistical models in S. Chapman and Hall, London

Charlson RJ, Lovelock JE, Andreae MO, Warren SG (1987) Oceanic phytoplankton, atmospheric sulfur, cloud albedo and climate. Nature 326:655-661

Davidson AT, Bramich D, Marchant HJ, McMinn A (1994) Effects of UV-B radiation on growth and survival of Antarctic marine diatoms. Mar Biol 119:507-515

Davidson AT, Marchant HJ (1992a) Protist interactions and carbon dynamics of a Phaeocystis-dominated bloom at an Antarctic coastal site. Polar Biol 12:387-395

Davidson AT, Marchant HJ (1992b) The biology and ecology of Phaeocystis (Prymnesiophyceae). In: Round FE, Chapman DJ (eds) Progress in phycological research, Vol 8. Biopress, Bristol, p 1-45

Davidson AT, Marchant HJ (1994) Comparative impacts of in situ UV exposure on productivity, growth and survival of
Antarctic Phaeocystis and diatoms. Proc NIPR Symp Polar Biol 7:53-59

Eppley RW, Reid FMH, Strickland JDH (1970) Estimates of phytoplankton crop size, growth rate and primary production. In: Strickland JDH (ed) The ecology of the phytoplankton of La Jolla, California in the period April through September, 1967. Bull Scripps Inst Oceanogr 1:33-42

Fryxell GA, Kendrick GA (1988) Austral spring microalgae across the Weddell Sea ice edge: spatial relations found during a northward transect during AMERIEZ 83. Deep Sea Res 35:1-20

Garrison DL, Buck KR, Fryxell GA (1987) Algal assemblages in the Antarctic pack ice and in ice-edge plankton. J Phycol 23:564-572

Gibson JAE, Garrick RC, Burton HR, McTaggart AR (1990) Dimethylsulfide and the alga Phaeocystis in Antarctic coastal waters. Mar Biol 104:339-346

Helbling EW, Villafañe V, Holm-Hansen O (1994) Effects of Ultraviolet radiation on Antarctic marine phytoplankton photosynthesis with particular attention to the influence of mixing. In: Weiler CS, Penhale PA (eds) Ultraviolet radiation in Antarctica: measurements and biological effects. Antarctic Research Series, Vol 62. American Geophysical Union, Washington, DC, p 207-228 
Karentz D (1991) Ecological considerations of Antarctic ozone depletion. Antarct Sci 3:3-11

Karentz D (1994) Ultraviolet tolerance mechanisms in Antarctic marine organisms. In: Weiler CS, Penhale PA (eds) Ultraviolet radiation in Antarctica: measurements and biological effects. Antarctic Research Series, Vol 62. American Geophysical Union, Washington, DC, p 93-110

Karentz D, Cleaver JE, Mitchell DL (1991a) Cell survival characteristics and molecular responses of Antarctic phytoplankton to ultraviolet-B radiation. J Phycol 27 $326-341$

Karentz D, McEwan FS, Land KM, Dunlap WC (1991b) A survey of micosporine-like amino acid compounds in Antarctic marine organisms: potential protection from ultraviolet exposure. Mar Biol 108:157-166

Karentz D, Spero HJ (1995) Response of Phaeocystis population to ambient fluctuations of UVB radiation caused by Antarctic ozone depletion. J Plankton Res 17 (9): $1771-1789$

Lubin D, Frederick JE, Booth CR, Lucas $T$, Neuschuler D (1989) Measurements of enhanced springtime ultraviolet radiation at Palmer Station, Antarctica. Geophys Res Lett 16:783-785

Marchant HJ, Davidson AT (1991) Possible impacts of ozone depletion on trophic interactions and biogenic vertical carbon flux in the Southern Ocean. In: Weller G, Wilson CL, Severin $B A B$ (eds) Proceedings of the International Conference on the Role of Polar Regions in Global Change. Vol 2, Geophysical Institute, Fairbanks, p 397-400

Marchant HJ, Davidson AT, Kelly GJ (1991) UV-B protecting pigments in the marine alga Phaeocystis pouchetii from Antarctica. Mar Biol 109:391-395

McMinn A, Heijnis H, Hodgson D (1994) Minimal effects of UVB radiation on Antarctic diatoms over the past 20 years. Nature 370:547-549

Responsible Subject Editor: S. Chisholm, Cambridge, Massachusetts, USA
Mitchell BG, Holm-Hansen O (1991) Observations and modelling of Antarctic phytoplankton crop in relation to mixing depth. Deep Sea Res 38:981-1007

Smith RC, Prezelin BB, Baker KS, Bidigare RR, Boucher NP, Coley T, Karentz D, MacIntyre S, Matlick HA, Menzies D, Ondrusek M, Wan Z, Waters KJ (1992) Ozone depletion: ultraviolet radiation and phytoplankton biology in Antarctic waters. Science 255:952-959

Smith WO Jr, Nelson DM (1986) Importance of ice edge phytoplankton production in the Southern Ocean. BioSci 36:251-257

Trodahl HJ, Buckley RG (1989) Ultraviolet levels under sea ice during the Antarctic spring. Science 245:194-195

Vernet M, Brody EA, Holm-Hansen O, Mitchell, BG (1994) The response of Antarctic phytoplankton to ultraviolet radiation: absorption, photosynthesis and taxonomic composition. In: Weiler CS, Penhale PA (eds) Ultraviolet radiation in Antarctica: measurements and biological effects. Antarctic Research Series, Vol 62. American Geophysical Union, Washington, DC, p 143-158

Veth $C$ (1991) The evolution of the upper water layer in the marginal ice zone, austral spring 1988, Scotia-Weddell Sea. J Mar Syst 2:451-464

Weiler CS, Penhale PA (1994) Preface. In: Weiler CS, Penhale PA (eds) Ultraviolet radiation in Antarctica: measurements and biological effects. Antarctic Research Series, Vol 62. American Geophysical Union, Washington, DC, p xi-xii

Worrest RC, Thomson BE, Van Dyke H (1981) Impact of UV-B radiation upon estuarine microcosms. Photochem Photobiol 33:861-867

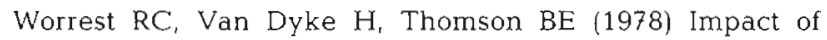
enhanced simulated solar ultraviolet radiation upon a marine community. Photochem Photobiol 27:471-478

Zar JH (1984) Biostatistical analysis, 2nd edn. Prentice-Hall, Englewood Cliffs, NJ

Manuscript first received: October 27, 1995

Revised version accepted: February 20, 1996 